\title{
A COMPLEXIDADE DA SANÇÃO PENAL DOS ATOS DE ASSASSINOS EM SÉRIE
}

\section{THE COMPLEXITY OF THE PENAL SANCTION FOR THE ACTS OF SERIAL}

\section{KILLERS}

RESUMO: O presente artigo possui como objeto de estudo a figura do assassino em série. Inicialmente temse a evolução histórica com a apresentação do termo serial killer, seguido pela explanação de suas principais características elucidando questões como o modus operandi, assinatura, local do crime e vitimologia, entre outros aspectos comuns na personalidade dos homicidas seriais. Foi feita a diferenciação entre indivíduos psicóticos e de personalidade psicopata. Ademais, realizou-se uma análise sobre a sanção penal adequada para que a finalidade da pena adotada pela Teoria da Pena Unificada seja alcançada, verificando qual a imputabilidade cabível aos serial killers. Outrossim, foi feita uma breve análise da PLS 140/2010, a qual prevê legalmente uma punição aos indivíduos diagnosticados como assassinos em série. Por fim, foi feita uma pesquisa sobre o julgamento do "maníaco do parque", concluiu-se, assim, que a responsabilidade penal do assassino em série concerne num ponto complexo que exige considerável estudo por profissionais qualificados e de diversas áreas, fazendo-se necessária uma visão diferenciada no que tange a esse tipo de personalidade; uma vez que não possui expectativa de cura e nem mesmo ressocialização.

Palavras-chave: Assassino em série; Imputabilidade; Psicopatia; Pena; Medida de segurança.

ABSTRACT: The present article has as object of study a figure of the serial killer. At first, it presents a historical evolution with a presentation of the term serial killer, followed by an explanation of the main characteristcs, clarifying issues as the modus operandi, signature, crime scene and victimology, as well as other common aspects in the personality of the serial killers. Was made a differentiation between psychotic and psychopathic individuals. In addition, an analysis of the suitable penal sanction for the application of the penalty adopted by the Theory of Unified Penalty (Teoria da Pena Unificada) was carried out, being achieved, verifying what is the applicable imputability for serial killers. Moreover, a brief analysis of PLS 140/2010 was made that predict a legally qualified punishment for individuals diagnosed as serial killers. Finally, a survey was carried out on the trial of the "park maniac", what concluded that a criminal resoponsability of a serial killer related to a complex point that requires study by professionals from different areas, that way is necessary a differentiated view in refference of this personality type, since it doesn't have the expectation of cure or even resocialization.

Keywords: Serial killer; Imputabillity; Psychopathy; Penalty; Security measure. 


\section{INTRODUÇÃO}

O intuito do presente trabalho está na apresentação dos seriais killers como doentes mentais, conceituando os perfis criminais que podem vir a ser considerados ou não, expondo uma discussão a respeito da punição que deve ser estabelecida para os referidos casos.

Assassinos em série são considerados pelo Federal Bureau of Investigation (FBI) como indivíduos que cometem homicídios de maneira sequencial, atuando do mesmo modo (modus operandi) e com um padrão de vítima específico, deixando na cena do crime uma assinatura. Para que uma pessoa seja considerada Serial Killer, deve agir desse modo por no mínimo três vezes em locais distintos. Tal conceito, conforme afirmado por Schechter (2013), tornou-se uma definição ampla demais ao mesmo tempo que estrita demais, e por esse motivo é uma conceituação amplamente discutida e por muitos negada, uma vez que esses homicidas podem agir em um local específico e vir aperfeiçoando seu modo de agir durante os anos.

De acordo com Carvalho (2018), a conceituação de assassino em série é um instituto que mesmo já tendo sofrido inúmeras mutações em sua hermenêutica, ainda há de sofrer muito mais, incluindo o ponto de vista jurídico, se consolidando como um fenômeno dinâmico no espaço-tempo.

Sendo assim, iniciaremos o estudo com o intuito de conhecer melhor os doentes mentais, considerados psicopatas em seu maior nível e a carência de uma punição específica para esses indivíduos, os quais, por serem julgados por crimes contra a vida, acabam caindo em um julgamento feito por pessoas sem o conhecimento necessário para puni-los.

Conforme mencionado por Varanda (2017), as expressões psicopatas, assassinos em série, sociopata ou maníaco são usadas com muita casualidade e hoje perderam seus significados, não sendo dada a importância necessária na complexidade trazida por elas.

É fato que não existe a ressocialização de indivíduos diagnosticados como psicopatas e que, no meio carcerário, eles são considerados como seres irrecuperáveis; ademais, a não existência de uma legislação específica no país para tratar do assunto mostra o quão desatualizado se encontra nosso aparato jurídico.

A imputabilidade é entendida como a consciência do agente no que se refere à ilicitude do ato cometido, ou seja, a compreensão de que aquilo que ele fez é crime. Já a inimputabilidade, conceituada no artigo 26 do Código Penal, isenta de pena a pessoa que possui doença mental ou desenvolvimento mental incompleto, a qual era incapaz ao tempo do crime de entender o aspecto ilícito do fato ou de determinar-se conforme esse entendimento. É válido ressaltar que os psicopatas homicidas geralmente sabem exatamente o que estão fazendo, conhecendo a ilicitude dos seus atos, mas isso não tem potencialidade de os fazer parar.

A problemática se encontra no momento em que não é possível fazer uma elucidação solidificada da situação psiquiátrica desses indivíduos, uma vez que o Estado não possui aparato suficiente para punir esses psicopatas homicidas, podendo vir a ser considerados imputáveis e cumprirem pena privativa de liberdade, bem como serem considerados inimputáveis ou semi-imputáveis, podendo ter a pena substituída pela medida de segurança. Nota-se que em ambas as penas existe um limite de cumprimento, o que traz a possibilidade de, 
quando em liberdade, o psicopata voltar a matar. Desse modo, o objetivo do trabalho é discutir uma possível punição a esses indivíduos, de maneira a manter a sociedade livre de uma, já esperada, reincidência.

Nessa perspectiva, este trabalho consiste em um estudo que abarcará tanto o universo jurisdicional quanto o da Psicologia. Para tanto, será utilizado o método de pesquisa qualitativa, por meio do qual servirão como aportes teóricos legislações, doutrinas, livros, artigos, estudos de casos, a fim de que possamos analisar pontos cruciais para o estudo desses indivíduos, com o exemplo de modus operandi, assinaturas e classificações.

Além disso, o objeto do presente artigo consiste em discutir quais outras espécies de punição poderiam ser consideradas ao assassino serial, a partir da análise da sua personalidade e o modo como ele e encontra inserido na sociedade, afinal tais indivíduos possuem distúrbio antissocial, o que dificulta sua reinserção.

Por fim, será trazida uma especificidade ao assunto, a partir da interpretação do ordenamento jurídico brasileiro, pela decisão de aplicar medida de segurança ou penas adequadas e proporcionais em cada caso concreto, juntamente com a análise do projeto de lei 140/2010.

\section{ASPECTOS HISTÓRICOS E PSICOLÓGICOS}

\subsection{Histórico}

Conforme registros comprobatórios de Casoy (2017) o termo "Serial Killer" não foi criado, mas adaptado e expandido para todo o mundo por meio do agente especial do Federal Bureau of Investigation (FBI), Robert Ressler, que foi um dos fundadores da chamada Unidade de Ciência Comportamental, a qual ficou conhecida também como "Caçadores de Mente".

Apesar de ser uma expressão relativamente nova, não podemos dizer o mesmo desses indivíduos. Antes de possuírem uma nomenclatura específica, os homicidas seriais se encontravam na categoria de assassinos em massa, que são indivíduos que matam quatro ou mais pessoas em um único episódio e no mesmo local. Podemos citar como exemplo os indivíduos que entram em colégios e saem atirando aleatoriamente. Quando a temática é analisada mais precisamente, é perceptível o grande equívoco na classificação.

No passado, conforme afirma Schechter (2013), qualquer um poderia escapar impune de assassinatos em série, desde que estivessem atacando pessoas sem relevância para a sociedade, como eram consideradas as prostitutas e moradores de rua. Ainda conforme registros, pessoas que sentiam prazer ao cometer atos cruéis, de tortura e mutilação, não eram consideradas necessariamente criminosas, podendo, como uma maneira de aliviar suas vontades, adentrar ao exército e assassinar homens, mulheres e crianças livremente. 
O mais antigo assassino a ser reconhecido como tal é "Jack, o Estripador"1 um homicida que atuou em Londres, no final do século XIX, tendo feito pelo menos cinco vítimas, sendo todas mulheres e prostitutas. Jack não é considerado o primeiro existente, mas como citado pelo autor da obra "Serial Killers: Anatomia do mal" (SCHECHTER, 2013), foi o primeiro a tornar-se celebridade internacionalmente famosa nos meios de comunicação.

No Brasil, um caso teve grande repercussão. Ocorrido por volta dos anos de 1863-1864, em Porto Alegre, ficou conhecido como "Açougue Humano da Rua do Arvoredo" e foi marcado pela atuação de dois homicidas seriais: Catarina Palse e José Ramos. O casal praticava atos de canibalismo, muito comuns em tais personalidades, tendo assim desossado cadáveres, fabricado e vendido a carne das suas vítimas para toda a cidade. A história ficou conhecida como "o maior crime da Terra".

\subsection{Aspectos psicológicos}

\subsubsection{Características dos Serial Killers}

Não é possível diagnosticar um psicopata serial killer na infância, uma vez que não existe uma personalidade formada. Todavia existem indícios conhecidos, como "terrível tríade", que se encontram presentes no histórico da maioria dos assassinos em série, consistindo em: ENURESE em idade avançada, maus tratos em animais e pirotecnia. É válido ressaltar que, assim como a conceituação dos serial killers, tais características não são imutáveis e podem ser diferentes de um indivíduo para outro.

A ENURESE em idade avançada, que consiste em urinar na cama até a idade posterior aos cinco anos, pode ser consequência de traumas ou abusos ocorridos na infância. Segundo Schechter (2013), um total de $60 \%$ dos homicidas sexuais ainda sofria com tais distúrbios na adolescência, como o serial killer Alton Coleman, o qual, por sofrer com constante incontinência urinária, recebeu o apelido depreciativo de "Mijão".

Outro ponto que compõe a tríade consiste nos maus tratos aos animais. As primeiras vítimas dos serial killers são comumente seres de fácil dominação, como animais de estimação e pássaros. A maioria desses indivíduos iniciam seus episódios criminosos através da tortura de animais indefesos, para alimentar sua sensação de domínio. Com isso, estudos comprovam que pessoas que têm coragem de machucar os animais possuem também grande potencial para fazer o mesmo com outros indivíduos.

O último ponto da "Terrível Tríade" consiste em que os assassinos em série depositam sua raiva não só na tortura dos animais, como também em prédios públicos, monumentos e propriedades, seja depredando ou incendiando. Sendo assim, tais homicidas possuem certa tendência à pirotecnia.

\footnotetext{
${ }^{1}$ CASOY, Ilana. Arquivos Serial Killer: Louco ou cruel? e Made in Brazil. Rio de Janeiro: DarkSide Books, 2017.

${ }^{2}$ Freitas, Décio. O maior crime da Terra: O açougue humano da rua do Arvoredo (1863-1864). Porto Alegre: Editora Sulina/Meridional. 1996.

${ }^{3}$ SCHECHTER, Harold. Serial Killer: Anatomia do Mal. Rio de Janeiro: DarkSide Books, 2013.
} 
Segundo Casoy (2017), os assassinos seriais podem ser classificados em quatro tipos: visionário, que é aquele indivíduo completamente insano, considerado psicótico; missionário, esse tipo não aparenta ser psicótico socialmente, mas acredita ter o dever de livrar o mundo daquilo que julga ser imoral ou indigno; emotivo, esses matam apenas por prazer; e, por fim, o sádico, o assassino sexual, cujo prazer liga-se diretamente ao sofrimento de sua vítima.

São quatro os tipos de comportamentos que possivelmente o agressor utilizará na cena do crime, a saber: assinatura, modos operandi, local do crime e vitimologia. O serial killer sempre assina seus crimes. Como uma digital, é algo próprio do indivíduo, e sempre estará ligada à necessidade que ele possui de cometer o ato, como exemplo do Serial Killer que utiliza amarrações em suas vítimas. Alguns têm a necessidade de carregar consigo algo que possa ser recordado posteriormente, levando peças de roupa ou até mesmo partes do corpo de suas vítimas. Quando o assassino deixa de concluir seu ritual, subentende-se que tenha sido impedido por vontade contrária, como barulhos ou comportamentos inesperados da vítima.

O tipo de padrão comportamental é conhecido como modos operandi e pode ser definido pelo tipo de arma utilizada, os locais utilizados, o tipo de vítima e a forma de agir do assassino durante a execução do crime, visto que alguns preferem envenenar, outros sufocar, torturar, esfaquear ou estuprar, antes de matar ou até mesmo depois. O modus operandi pode ser modificado, podendo o assassino adicionar ou retirar algo que não deu certo da última vez em seu ritual.

\begin{abstract}
Os institutos utilizados são verificados como a Traição Moral, Traição Material, Emboscada e Dissimulação. A traição primeiramente é compreendida como a deslealdade, perfídia com que é cometido o fato criminoso. Sendo descrita como Moral, é concebida no tocante de que o agente atrai a vítima para determinado local onde se consumará o crime. Fica claro dessa forma a intenção do serial killer brasileiro, Francisco Assis Pereira, O Maníaco do Parque, da cidade de São Paulo. A Traição Material é quando o agente atinge a vítima pelas costas. Emboscada, porém, é a denominada tocaia, fato de o agente esperar dissimuladamente a vítima no local de sua passagem para o cometimento do crime. Por conseguinte, Dissimulação é esconder a vontade ilícita para apanhar o ofendido desprevenido. (NEP-FDCL, 2012)
\end{abstract}

A partir da encenação feita pelo assassino no local do crime, é possível descobrir várias características de sua personalidade, tal como separá-lo entre organizado e desorganizado. A maneira como se encontra a vítima também deixa claro se o suspeito é próximo ou conhecido dela, já que, quando são próximos, raramente encontra-se a vítima despida.

Outra característica dos homicidas seriais é o padrão estabelecido por eles ao escolher suas vítimas. Geralmente esses indivíduos possuem um tipo específico de vitimologia, como exemplo de Francisco de Assis Pereira, o "Maníaco do Parque", que escolhia sempre mulheres jovens de cabelos cacheados e castanhos. Logo, pessoas diferentes do padrão estabelecido não lhe despertavam o interesse.

Como já exposto, assassinos seriais podem ser divididos em duas categorias: organizados e desorganizados, que consiste na maneira como agem tanto no dia a dia quanto durante seus atos criminosos.

\footnotetext{
${ }^{4}$ CASOY, Ilana. Arquivos Serial Killer: Louco ou cruel? e Made in Brazil. Rio de Janeiro: DarkSide Books, 2017.
} 
Os assassinos organizados são bem-apessoados, possuem inteligência acima da média, mas, no geral, não são realizados profissionalmente, com uma tendência por profissões como motorista de caminhão, bombeiros e barman, que os enalteçam como homens. Outrossim, são sexualmente competentes e têm uma mulher importante nas suas relações.

\begin{abstract}
Muitos homicidas-seriais têm inteligência privilegiada (Ed Kemper é gênio, com um QI superior a 140), o que se mostra paradoxal, porquanto, ao tempo em que eram inteligentes, tiveram fraco ou péssimo desempenho em seus resultados escolares ou universitários, onde mais da metade deles não conseguiram sequer concluir o ciclo escolar, obtendo notas medíocres. (BONFIM, 2004, p.66)
\end{abstract}

No que tange ao crime em si, suas cenas são planejadas e controladas, possuindo um temperamento muito controlado durante a execução do ato e, após findá-lo, levam embora consigo sua arma e instrumentos utilizados durante o crime. Suas vítimas geralmente são mulheres, com algum traço em particular, as quais, na maioria das vezes, têm uma morte dolorosa e lenta. Levam o corpo e muitas vezes o esquartejam para que a identificação pela polícia seja dificultada.

Diferente dos homicidas organizados, os desorganizados comumente possuem inteligência abaixo da média; geralmente possuem trabalhos especializados, nos quais não possuem contato com o público; além disso, suas vítimas são selecionadas ao acaso, seus crimes possuem violência exagerada, "overkill”" (necessitam mais do que matar, mas agredir, ferir, torturar), comumente atacam suas vítimas sexualmente após a morte e, por não terem nenhum tipo de cuidado, são mais facilmente localizados.

\title{
2.2.2 Psicopatia x Psicose
}

Conforme o que afirma Schechter (2013), psicopatas não são legalmente insanos, conseguem efetuar a distinção entre o certo e o errado. Suas características mais marcantes são a falta de empatia, não sentem culpa ou remorso.

\footnotetext{
Por exemplo, quando uma das vítimas de Jefferey Dahmer, algemada e sangrando, conseguiu fugir e saiu correndo rua afora, Dahmer calmamente persuadiu a polícia a retornar o jovem aos seus cuidados. Em seguida levou-o de volta ao seu covil diabólico e o matou. (SCHECHTER, 2013, p.27)
}

A psicopatia pode ser diagnosticada desde a infância, a partir de alguns traços de personalidades demonstrados, a exemplo do desrespeito por normas, da facilidade de criar relacionamentos, da destreza em falar o que o próximo deseja ouvir, de frustrar-se facilmente, tendo reações de agressividade e de possuírem um egocentrismo exagerado.

De acordo com a Teoria do Link, criada por Marcelo Robis Francisco Nassaro (2016), aponta-se como um dos principais “alertas" os maus tratos a animais, uma vez que pessoas que os cometem apresentam traços de insensibilidade e tendências a praticar violência contra outros indivíduos muito facilmente. 
Ao se dividir todos os crimes cometidos em um grupo de crimes violentos (lesões corporais, roubo, ameaça, homicídio etc.) e em outro grupo de crimes não violentos, verificou-se que metade dos crimes praticados por quem tinha histórico criminal de maus-tratos aos animais foi de crimes violentos contra as pessoas. (NASSARO, 2016)

Já a psicose pode ter seu conceito definido como um transtorno mental grave. Psicóticos vivem em um mundo criado por eles, sofrem de alucinações e delírios. Acreditam viver numa realidade diferente, relacionando-se com seres inexistentes e objetos inanimados. Outrossim, quando não se encontram em surto, esses indivíduos possuem uma vida normal, alimentam-se, cuidam-se e, algumas vezes, nem se lembram dos atos que cometeram durante o tempo em que se deu o transe.

Os Serial Killers podem estar inseridos em ambas as definições. Conforme Bonfim (2004), quando se tratam de doentes mentais diagnosticados como psicóticos, muitos homicidas seriais se julgam como Deus ou o Demônio e acreditam ter direito de vida sobre os “mortais comuns", acreditam até que vieram ao mundo com o objetivo de purificar a espécie humana.

Quando são diagnosticados como psicopatas, os assassinos em série revelam-se mentirosos profissionais, capazes de enganar a polícia, como é o caso do famoso serial killer americano Ted Bundy ${ }^{5}$, grande manipulador e responsável por mais de 30 assassinatos em diversos locais dos Estados Unidos.

Significaria dizer que, embora sabendo o correto e o errado sobre a conduta humana, não teria o pleno autodomínio ou autodeterminação para agir de acordo com esse entendimento, Revela-se mestre da manipulação, porquanto não sente angústia ou remorso, agindo linearmente sem emoção tanto quando delibera um plano criminoso quando se dispõe a executá-lo ou a recordar, posteriormente, sobre ele. (BONFIM, 2004, p. 82)

Por serem pessoas muito fora dos padrões acabam necessitado um tratamento diferenciado no que tange o tipo de punição que irão receber, levando-se em conta sua personalidade, tipo de crime, métodos utilizados e um sério estudo relacionado as chances de reincidência.

\section{ASPECTOS JURÍDICOS}

\subsection{Conceito de impuptabilidade}

A imputabilidade consiste em um dos elementos em que é composta a culpabilidade, na qual pode ser entendida como a capacidade que o agente deve ser responsabilizado pelo fato típico e ilícito, ou seja, de tê-lo a si imputado.

De acordo com Rogério Greco (2016), a imputabilidade é a regra e a inimputabilidade a exceção, sendo a segunda aferida apenas em casos referidos no Art. 26 do Código Penal:

Art. 26 - É isento de pena o agente que, por doença mental ou desenvolvimento mental incompleto ou retardado, era, ao tempo da ação ou da omissão, inteiramente incapaz de

${ }^{5}$ CASOY, Ilana. Arquivos Serial Killer: Louco ou cruel? e Made in Brazil. Rio de Janeiro: DarkSide Books, 2017. 
entender o caráter ilícito do fato ou de determinar-se de acordo com esse entendimento. (Redação dada pela Lei 7.209, de 1984)

Por conseguinte, Carvalho (2018) definiu como imprescindível a presença de dois elementos para a imputabilidade, sendo esses: intelecto, ou seja, entendimento dos seus atos e volitivo, que seja a capacidade de controlar seus impulsos e agir de acordo com o caráter ilícito do fato.

Dessa maneira, é perceptível que o Brasil adota o caráter biopsicológico para a aferição da inimputabilidade, na qual serão inimputáveis os indivíduos que portarem algum tipo de doença mental ou alguma deficiência no desenvolvimento mental, sendo incapacitado de entender a ilicitude do fato. Aos inimputáveis será adotada a medida de segurança como consequência de sua absolvição.

São dois os elementos que devem se trazer presentes para que haja imputabilidade: intelectivo, consistente na higidez psíquica que permita ao agente ter consciência do caráter ilícito do fato; e volitivo, em que o agente domina sua vontade, ou seja, exerce controle sobre a disposição surgida com o entendimento do caráter ilícito do fato, e se determina de acordo com este entendimento. (CUNHA, 2016, p. 287)

A semi-imputabilidade acontece quando o agente comete o ato ilícito e culpável, porém, por não ter pleno conhecimento do ato, acaba por ter sua pena reduzida. Ou seja, existe a aplicação de uma pena, contudo ela será diminuída.

\begin{abstract}
Se optar pela aplicação de uma pena privativa de liberdade ao assassino serial, estaríamos apenas restringindo os direitos do mesmo, sem contribuir de nenhuma forma para que este se restabeleça socialmente. E, respeitados os limites legais de pena, e também é importante frisar que o mesmo teria assegurado direito à progressão de regime, ou seja, este agente estaria algum tempo depois em liberdade, oferecendo perigo ainda maior à coletividade, pois diversos estudos apontam que a prisão causa a intensificação das compulsões dos criminosos com distúrbios mentais ou de personalidade. (RAMOS, 2017).
\end{abstract}

É importante frisar que, no sistema penal brasileiro, psicopatas são considerados imputáveis, afinal não são considerados mentalmente insanos, devendo sua imputabilidade ser esclarecida pelo laudo pericial apresentado.

\footnotetext{
Mais uma vez, cumpre frisar que o psicopata não é doente mental, logo não é inimputável (é possível que, além de traços de personalidade psicopática, o agente sofra de perturbações mentais, deficiências e afins; nestes casos, o laudo pericial estabelecerá em que grau isto ocorre, porém é importante frisar que por si só a psicopatia não diminui a capacidade do indivíduo). (CEOLIN; CARVALHO, 2016).
}

Sendo assim, os indivíduos portadores da personalidade psicopata deveriam ser amplamente analisados antes de ser estabelecida sua imputabilidade e tipo de pena, fazendo cumprir o princípio da individualização da pena. 
Conforme defendido por Nucci (2019), a individualização consiste na particularização de uma situação ou de um indivíduo, distinguindo uma coisa de outra, com objetivo de compreender o conteúdo, o alcance e a extensão do objeto de análise. O princípio baseia-se na não padronização da pena, de modo que a pena seria baseada de acordo com o que cometeu cada criminoso.

Tal princípio exerce uma grande importância para que seja efetivada uma fixação justa para cada circunstância. A individualização pode acontecer tanto durante a sentença condenatória quanto na fase de cumprimento de pena.

A individualização da pena tem previsão constitucional conforme o artigo $5^{\circ} \mathrm{XLVI}$ :

“5” - XVLI: a lei regulará a individualização da pena e adotará, entre outras, as seguintes: a) privação ou restrição da liberdade; b) perda de bens; c) multa; d) prestação social alternativa; e) suspensão ou interdição de direitos" (Redação dada pela Constituição Federal, 1988).

De acordo com Cunha (2015), a individualização da pena precisa ser observada em três momentos: inicialmente na definição do crime e sua pena; na imposição da pena pelo juiz; e por último na fase de execução da pena, momento em que os delinquentes serão classificados, de acordo com os seus antecedentes e personalidade, para que seja orientada a individualização da execução penais.

Desse modo, frente a situação particularizada enfrentada no julgamento de serial killers, tal princípio chega a ser fundamental para uma justa definição da pena, afinal, conforme será explanado, indivíduos que cometem assassinatos seriais precisam ser analisados com uma maior atenção. De acordo com o princípio da individualização, a pena que serve para um indivíduo pode ser completamente ineficaz para outro, devendo se encaixar especialmente para cada um.

\subsection{Das sanções penais}

3.2.1 Da medida de segurança e das penas

É válido ratificar a possibilidade de reincidência por parte desses indivíduos, chegando a ser praticamente impossível a ressocialização de pessoas diagnosticadas com psicopatia.

De acordo com o sistema penal brasileiro, àqueles que são imputáveis serão impostas penas como medidas de punição, bem como serão impostas medidas de segurança para aqueles que forem considerados semi-imputáveis e inimputáveis.

Conforme explanam Ceolin e Carvalho (2016), a pena tem objetivo de punir o agente, demonstrando a reprovação de sua conduta típica e antijurídica, visando a prevenção para que não sejam cometidos novos delitos pelo mesmo indivíduo; já a medida de segurança objetiva o tratamento do indivíduo.

De acordo com o conceito de Masson (2017), medida de segurança consiste em uma modalidade de sanção penal, que possui finalidade exclusivamente preventiva e de caráter terapêutico, destinando-se a tratar 
inimputáveis e semi-imputáveis portadores de periculosidade, com o escopo de evitar a prática de futuras infrações penais.

Pelo mesmo pensamento, tem-se o conceito de Mirabete (2002), que afirma que a medida de segurança fundamenta-se em aplicação na periculosidade, diferenciando da pena, a qual é baseada na culpabilidade e tem como objetivo a prevenção e recuperação dos indivíduos delinquentes com um tratamento curativo.

Os serial killers se enquadram nos indivíduos que portam uma devida periculosidade e, como já dito, tendem a reincidir com muita facilidade. $\mathrm{O}$ artigo 96 do elucida os tipos de medida de segurança:

Art. 96 As medidas de segurança são:

I - Internação em hospital de custódia e tratamento psiquiátrico ou, à falta, em outro estabelecimento adequado.

II - Sujeição a tratamento ambulatorial.

Parágrafo único - Extinta a punibilidade, não se impõe medida de segurança nem subsiste a que tenha sido imposta. (Redação dada pela Lei 7.209, de 1984)

Por ter como objetivo a cura e prevenção, a medida de segurança não possui uma delimitação de tempo, devendo durar enquanto houver a necessidade de manutenção da saúde mental do indivíduo. De acordo com Chagas (2016), terá continuidade, até o momento em que for constatada, mediante perícia médica, a chamada cessação de periculosidade do agente, inclusive, sendo capaz de se manter até a morte do paciente.

O Supremo Tribunal Federal possui entendimento de que não é possível manter um indivíduo em medida de segurança por período maior que 30 anos.

MEDIDA DE SEGURANÇA - PROJEÇÃO NO TEMPO - LIMITE. A interpretação sistemática e teleológica dos artigos 75, 97 e 183, os dois primeiros do Código Penal e o último da Lei de Execuções Penais, deve fazer-se considerada a garantia constitucional abolidora das prisões perpétuas. A medida de segurança fica jungida ao período máximo de trinta anos. (HC 84219/Min. Marco Aurélio, Primeira Turma, 2005)

Tal entendimento pode vir a sofrer alteração em vista da aprovação da Lei $13.964 / 2019^{6}$, a qual majora o tempo máximo de cumprimento das penas privativas de liberdade para 40 anos.

A partir da redação dada pelo Art. 59 Código Penal (1984) confere-se a Teoria Unificadora da Pena, na qual traz a pena como uma retribuição ao condenado pelo mal causado à sociedade, e também é um modo de prevenir que a conduta não volte a se repetir; outro objetivo seria a ressocialização do agente por meio da punição.

Art. 59 - O juiz, atendendo à culpabilidade, aos antecedentes, à conduta social, à personalidade do agente, aos motivos, às circunstâncias e consequências do crime, bem como ao comportamento da vítima, estabelecerá, conforme seja necessário e suficiente para reprovação e prevenção do crime.(Redação dada pela Lei nº 7.209, de 1984)

${ }^{6}$ BRASIL. Lei 13.964, de 24 de dezembro de 2019. Aperfeiçoa a legislação penal e processual penal, Brasilia, 24 de dez. de 2019. 
Conforme já explanado, a pena possui objetivo de punição da conduta típica do agente, demonstrando a reprovação dos seus atos. Conforme Ceolin e Carvalho (2016), as penas são atribuídas a agentes imputáveis e semi-imputáveis, enquanto as medidas de segurança, atualmente, se aplicam, sobretudo, aos inimputáveis; entretanto, há casos também em que semi-imputáveis são passíveis de punição.

Pena é espécie de sanção penal consistente na privação ou na restrição de determinados bens jurídicos do condenado, aplicada pelo Estado em decorrência do cometimento de uma infração penal, com as finalidades de castigar seu responsável, readaptá-lo ao convívio em comunidade e, mediante a intimidação endereçada à sociedade, evitar a prática de novos crimes ou contravenções penais. (MASSON, 2012, p.540).

A pena tem como objetivo a prevenção para que não sejam repetidos os atos por outras pessoas, bem como a ressocialização dos indivíduos condenados, para que sejam recuperados e aptos para uma reinserção na sociedade. Porém, é importante analisar se o objetivo da pena alcança a personalidade psicopata serial killer, afinal estudos mostram que a psicopatia não tem cura.

Haja vista que uma das finalidades da pena é a reinserção do indivíduo na sociedade, sabe-se que, mesmo que possa compreender o caráter ilícito de suas ações, os assassinos seriais não conseguem ter algum sentimento pela vítima, não são dotados de empatia e não conseguem sentir arrependimento pelos atos cometidos.

(...) uma das finalidades da pena tem por objetivo recuperar o condenado e reinserir o mesmo na sociedade, fica a lacuna, portanto, de uma fundamentação acerca da possibilidade de recuperar algo que nunca fez parte desse sujeito, haja vista ser ele desprovido de sentir o mínimo de arrependimento pelo fato reprovável que possa ter cometido. (CHAGAS, 2016,p.41).

Uma vez que os serial killers são pessoas dotadas de personalidade psicopata, nasce a necessidade de uma legislação que abranja as peculiaridades que devem ser adotadas ao lidar com esses indivíduos de modo a protege-los e proteger a sociedade fazendo-se o uso do já comentado princípio da individualização da pena.

\subsection{O Serial Killer no Direito Penal Brasileiro e o PLS 140/2010}

É ainda inexistente no Direito Brasileiro o conceito penal de Serial Killer, o que faz nascer um problema, uma vez que já é conhecida a diferença entre um assassino comum e um assassino em série, não sendo possível a ressocialização do segundo em face de sua característica incurável de psicopatia.

A falta da conceituação torna nosso sistema falho e desatualizado, afinal não é contabilizado apenas um ou dois casos de homicídios seriais no país. A legislação específica se torna necessária se analisamos, por exemplo, os homicídios de "Pedrinho Matador", indivíduo que deixou mais de cem vítimas e cumpriu 34 anos de pena privativa de liberdade, uma vez que foi solto e voltou a cometer assassinatos.

${ }^{7}$ CASOY, Ilana. Arquivos Serial Killer: Louco ou cruel? e Made in Brazil. Rio de Janeiro: DarkSide Books, 2017. 
Outro caso que podemos levar em consideração, ao exemplificar a dificuldade de julgamento dos referidos assassinos, é o "Maníaco do Parque", que estuprou e matou ao menos onze mulheres em um parque da cidade de São Paulo. Ademais, pela maneira que praticava os atos, foi levantada a questão da sua imputabilidade em razão dos traços de psicopatia apresentados. No caso em tela, a decisão por sua imputabilidade se deu por acreditarem que o indivíduo era completamente capaz de compreender suas ações.

É espantoso como ele descreve seus atos de maneira fria, sem alterar o tom da voz e não demostrar arrependimento ou remorso. Francisco parece se orgulhar de seus crimes; descreve-os sem sentir qualquer tipo de constrangimento. Ao executá-los chegou a praticar canibalismo, se masturbar diante do corpo da vítima e cometer necrofilia. (COELHO, 2017).

Ao apresentar este tipo de característica como canibalismo, necrofilia, nota-se a dificuldade em diagnosticar se o indivíduo possui algum tipo de anormalidade psíquica (psicótico) ou um transtorno de personalidade (psicopatia); nesse sentido, faz-se a dificuldade de defini-los.

Outrossim, é algo comum os casos protagonizados por homicidas seriais irem a júri popular. De acordo com Carvalho (2018), ocorre de o júri condenar o réu e, por esse motivo, o juiz, caso esse venha a ser atestado como semi-imputável, utilizará da causa diminuidora de pena e, assim, o incorrigível voltará ao convívio da sociedade.

Conforme apontado por SIENA (2012), o senador Romeu Tuma propôs introduzir a figura do homicida serial no Direito Penal Brasileiro, observando não existir até tal momento nenhuma menção a esses indivíduos no ordenamento. O projeto de lei tem o objetivo de definir o tratamento adequado a esses agentes, de maneira a diminuir as ameaças à segurança pública, trazendo, desse modo, uma maior segurança jurídica.

Tal projeto traria consigo a inserção dos $\S 6^{\circ}, \S 7^{\circ}, \S 8^{\circ}$ e $\S 9^{\circ}$ ao Art. 121 do Código Penal (1984) contendo neste a conceituação do que seria um assassino em série. Assim ficaria:

$\S 6^{\circ}$ Considera-se assassino em série o agente que comete 03 (três) homicídios dolosos, no mínimo, em determinado intervalo de tempo, sendo que a conduta social e a personalidade do agente, o perfil idêntico das vítimas e as circunstâncias dos homicídios indicam que o modo de operação do homicida implica em uma maneira de agir, operar ou executar os assassinatos sempre obedecendo a um padrão préestabelecido, a um procedimento criminoso idêntico.

$\S 7^{\circ}$ Além dos requisitos estabelecidos no parágrafo anterior, para a caracterização da figura do assassino em série é necessário a elaboração de laudo pericial, unânime, de uma junta profissional integrada por 05 (cinco) profissionais:

I-02 (dois) psicólogos;

II-02 (dois) psiquiatras;

III-01 (um) especialista, com comprovada experiência no assunto.

$\S 8^{\circ} \mathrm{O}$ agente considerado assassino em série sujeitar-se-á a uma expiação mínima de 30 (trinta) anos de reclusão, em regime integralmente fechado, ou submetido a 2 medidas de segurança, por igual período, em hospital psiquiátrico ou estabelecimento do gênero.

$\S 9^{\circ}$ É vedado a concessão de anistia, graça, indulto, progressão de regime ou qualquer tipo de benefício penal ao assassino em série. (PLS 140/2010 - Senador Romeu Tuma) 
Para a criação do projeto, o senador se justifica nos atos de um serial killer que assassinou seis jovens, afirmando que esses indivíduos não possuem nenhum tipo de compaixão, agindo friamente e que, por essa razão, devem-se adotar medidas extremas através de laudos periciais elaborados por profissionais. Porém, fica clara e evidente a necessidade de reformulação, uma vez que, em alguns pontos, o projeto vai de encontro com a Constituição Federal.

\begin{abstract}
Nesse diapasão, o artigo 75, do CódigoPenal, assevera que o cumprimento de penas privativas de liberdade não poderá exceder o limítrofe de 30 anos. Disso presume-se cristalino que o legislador concebeu uma inaceitável exceção à regra geral vigente e de duvidosa constitucionalidade.

Outrossim, a exigência de execução da pena sem progressão de regime, isto é, integral cumprimento da pena em regime fechado, além dos vetos concernentes à concessão de graça, anistia, indulto, ou qualquer tipo de benefício penal ao assassino em série, elucidam uma vacilante inconstitucionalidade, violando indubitavelmente a individualização da pena prevista no Art. $5^{\mathrm{a}}$ XLVI, da Constituição Federal (cláusula pétrea), e também jurisprudência uniformizada pelo Supremo Tribunal Federal. (CARVALHO, 2018, p. 09)
\end{abstract}

Resta clara a impossibilidade de aplicação do PLS 140/2010, quando observada diretamente por esse prisma, uma vez que, apontadas suas inconstitucionalidades, não possui aparato suficiente para sanar as problemáticas existentes.

\title{
3.4 Reincidência dos Serial Killers
}

Segundo o artigo 63 do Código Penal (1984), a reincidência é configurada quando o agente comete um novo crime, após a sentença que o tenha condenado por crime anterior transitar em julgado, no País ou no estrangeiro.

Conforme dados informados pelo Instituto de Pesquisa Econômica Aplicada (IPEA) ${ }^{8}$ referentes ao ano de 2015 a taxa de reincidência no Brasil atinge o número de $80 \%$. No geral, é perceptível que a finalidade não é atingida e, conforme Chagas (2016), o compromisso assumido pelo sistema penal de receber os presos adequadamente não é cumprido de forma devida, dessa forma colocando em risco a sociedade.

Em nosso Sistema Penitenciário, não existe um padrão de avaliação para analisar a personalidade do indivíduo encarcerado, de modo a prever uma possível reincidência; mesmo que haja, é importante ratificar a irrecuperabilidade dos serial killers e válido ressaltar a incurabilidade no que tange à psicopatia, uma vez que não se trata de uma doença mental, mas sim de um transtorno de personalidade.

Não existe tratamento eficaz para tais tipos criminosos, uma vez que suas personalidades assim estão formadas. Por não assimilarem os valores de nossa

\footnotetext{
${ }^{8}$ Dados fornecidos na pesquisa feita pelo Instituto de Pesquisa Econômica Aplicada de 2015 referente a Reincidência Criminal no B r a s i 1. em: 22 de maio de 2020.
} 
sociedade, por desconhecerem pressupostos básicos de uma convivência humana e respeitosa, tais psicopatas são chamados “personalidades antissociais". Quando presos, cada vez que conseguem enganar os psiquiatras que os avaliam e, assim, lograr obter a liberdade, tornam imediatamente a matar, tal como faziam ou, ainda, de forma mais elaborada e cruel. (BONFIM, 2004, p.92)

Um grande exemplo de reincidência é o caso de Francisco Rocha Pereira, conhecido como "Chico Picadinho", preso pelo homicídio e esquartejamento de uma mulher na década de 1960. Quando solto no ano de 1976, Chico voltou a utilizar o mesmo modus operandi, e, por esse motivo, voltou a ser preso e hoje ultrapassa os limites de permanência no cárcere.

Sendo preso em 1976 aos dias atuais, já se passaram 13 (treze) anos a mais que a pena máxima permitida pela legislação vigente e quase 20 (vinte) anos a mais do tempo que foi condenado à pena de reclusão. Em março de 2017, a juíza da Vara de Execuções de Taubaté, Sueli Zeraik de Oliveira Armani, concedeu liberdade ao preso. O juiz da Vara Cível, Jorge Alberto Passos, entrou com recurso por entender que Chico Picadinho não estava apto a voltar ao convívio social, alegando que o fato de estar na casa de custódia indicava o cumprimento de medida de albergue civil "diferenciada", pois a psiquiatria preferiu não mais assumir a responsabilidade de soltá-lo. (VILARINHO; LUCENA, 2019).

No que tange à prisão civil no ordenamento jurídico brasileiro, só é reconhecida para aqueles que se encontram inadimplentes em relação à pensão alimentícia; sendo assim, a interdição de Francisco foi um “improviso" para mantê-lo afastado do convívio social.

É perceptível o despreparo da legislação brasileira diante da situação extraordinária no que tange ao indivíduo portador do transtorno, carecendo de uma previsão legal, com objetivo de definir um tratamento ou punição específica, uma vez que a conjuntura merece uma atenção diferenciada, face ao grau de periculosidade apresentado por tais indivíduos.

\section{O JULGAMENTO DE FRANCISCO DE ASSIS}

\subsection{O maníaco do Parque}

No ano de 1998, entre os meses de janeiro e agosto, foram descobertos seis cadáveres já em estado de decomposição no Parque do Estado, localizado na cidade de São Paulo. As vítimas encontradas eram todas mulheres despidas, com idades entre 17 e 27 anos, de cabelos negros e longos, em posição típica de estupro; logo surgiu a suspeita de que havia um serial killer em atividade na região?.

Francisco de Assis Pereira, assim como a maioria dos assassinos em série, possuiu uma infância difícil, repleta de episódios de abusos sexuais, negligência familiar e da própria tendência psicopata de sua

${ }^{9}$ BEZERrA. Amanda de Melo. A história completa do maníaco do parque. Youtube. Disponível em: $<$ https://www.youtube.com/watch? $\mathrm{v}=\mathrm{u} 2 \mathrm{tGsZGtr8k}>$ Acesso em: 20 de aril de 2020 
personalidade. Antes de ser descoberto, ele já havia atacado outras mulheres sexualmente.

Logo após a descoberta dos corpos, foi encontrada uma carteira de identidade de uma das mulheres desaparecida, no vaso sanitário do estabelecimento onde ele trabalhava, e foi nesse momento que seu nome foi divulgado e as investigações foram em sua direção.

O "maníaco do parque", como ficou nacionalmente conhecido, teve seu rosto estampado em todos os veículos de comunicação da época, quando uma das mulheres sobreviventes o denunciou, fornecendo um retrato falado. Após a divulgação do fato, outras denúncias foram efetuadas por mulheres atacadas por Francisco anteriormente.

O modus operandi de Francisco iniciava-se na abordagem. Suas vítimas eram atraídas com promessas de constituir uma carreira de modelo, uma vez que ele se passava por fotógrafo de uma grande agência. O motoboy se utilizava da conveniência de sua profissão e convencia as mulheres a subirem voluntariamente em sua moto em direção ao parque, com o objetivo de fazer um ensaio fotográfico para a agência.

Ao chegar ao local do crime, Francisco cometia o assassinato através da asfixia mecânica, conhecida como esganadura, que consiste na constrição da região do pescoço, impedindo a passagem do ar. Após a morte da vítima, o motoboy as estuprava, mantendo um padrão ao arrumar o corpo, chamado de assinatura, que sempre era encontrado despido, com os joelhos afastados em posição sexual; além disso, muitas marcas de mordidas eram encontradas nos seios e ombros das vítimas. Foi dessa maneira que a polícia percebeu que os corpos encontrados eram de responsabilidade de uma única pessoa.

Assim sendo, ele pode ser considerado um indivíduo que carrega um histórico de transtorno de personalidade antissocial, uma vez que não sentia remorso ou sequer arrependimento pelos atos cometidos. Ele pode ser considerado um serial killer de classificação organizada, conseguindo manter uma vida socialmente ativa, apesar de não conseguir passar mais de um ano e meio nos estabelecimentos estava sempre trabalhando.

O que se depreende é que Francisco não é um doente mental, mas, sim, um criminoso com forte desvio de personalidade, capaz de seduzir suas vítimas através da boa conversa e persuasão, com intuito de satisfazer sua lascívia, sem nenhum tipo de piedade ou remorso. O típico psicopata. (SOUZA, 2019).

Ao tomar conhecimento de que seu nome havia sido divulgado, Francisco fugiu para o Sul do país, onde foi preso e, ao ser questionado, negou todas as acusações.

\subsection{Os julgamentos de Francisco de Assis Pereira}

O “maníaco do parque” foi a Júri Popular e, por fim, em 2002 foi condenado a 107 anos por roubar e violentar nove mulheres que sobreviveram ao ataque e a mais 121 anos pelas mortes confessadas. Bonfim (2004), principal promotor do referido caso, afirma que sempre acreditou que o maníaco do parque deveria ser julgado com imputável, tendo sido completamente responsável por seus atos. 
Nos processos de Francisco de Assis Pereira, se algum peso poderia ter a palavra da Ciência, era mais no sentido de reputá-lo plenamente responsável por seus atos - ou seja, que os atos lhe deveriam ser plenamente imputados. (BONFIM, 2004, p.109)

Apesar de o laudo psiquiátrico apontar que Francisco era portador de "transtorno antissocial de personalidade", segundo Edilson Mougenout Bonfim (2004) o perito Dr. Paulo Aragate Vasques somente firmou o laudo baseado na semi-imputablidade, pois compreendia a complexidade na discussão do caso, uma vez que, se firmasse na possibilidade de imputabilidade, temia o retorno do laudo para que fosse corrigido.

É válido ressaltar que à época do fato, de acordo com Bonfim (2010) não haviam discussões a respeito de serial killers no país, o que tornava imensamente difícil para os profissionais que trabalharam no caso enxergar a dimensão do problema que enfrentavam para diagnosticar o indivíduo. Os profissionais convidados a trabalhar no caso como peritos foram psiquiatras que nunca antes haviam feito qualquer perícia, já que se tratava de um caso atípico na Justiça Brasileira ${ }^{10}$.

Segundo a FENAPEF (2010), a construção das teses tanto da promotoria quanto da defensoria foram usadas como fontes de pesquisa e referências para futuros julgamentos, uma vez que se tornou um caso multidisciplinar, que envolvia questões de filosofia, psiquiatria e direito penal, fazendo com que o caso se tornasse famoso mundialmente.

Francisco se encontra preso desde 1998 na penitenciária Oswaldo Cruz-SP, o que nos leva a observar que, no máximo de sua pena, será solto em 2028. Mesmo após ter feito mais de 10 vítimas, durante seu período em atividade, o "maníaco do parque" poderá vir a conviver em sociedade, e, conforme já mencionado, com grandes chances de reincidência.

\section{CONSIDERAÇÕES FINAIS}

O tema proposto no presente estudo é de uma importância não só jurídica como também social, afinal trata-se de um assunto ainda considerado como muito distante da nossa realidade, porém de grande relevância, uma vez que é um conteúdo faltoso no ordenamento jurídico brasileiro.

Foi possível determinar diferentes traços da personalidade portadora do transtorno da psicopatia, através das características apresentadas, bem como das classificações organizado e desorganizado, os indícios manifestados durante a infância do indivíduo, conhecidos como "Terrível Tríade", que consiste em enurese, maus tratos aos animais e tendência à pirotecnia.

Conforme abordado, os homicidas seriais se encontram em um alto grau de psicopatia, o que os impede de sentir qualquer tipo de remorso ou arrependimento por suas vítimas; fazendo-se necessária uma melhor percepção dos legisladores, de modo a compreender melhor sobre qual tratamento ou punição seria viável para atender tamanha complexidade de tais personalidades.

\footnotetext{
${ }^{10}$ FENAPEF. Falta de estudos sobre serial killers dificulta julgamentos, afirma promotor. 2010. Disponível em: https://fenapef.org.br/29935/.Acesso em: 17 de novembro de 2020.
} 
De acordo com todo o exposto durante o estudo, é possível perceber o despreparo da legislação penal brasileira em lidar com indivíduos de personalidade psicopata, deixando a desejar no que se refere a um tipo de tratamento diferenciado, frente à situação particularizada, afinal, seria incoerente promover o encarceramento de um indivíduo serial killer, posto que, ao retorno do convívio social, estaria fadado a praticar novos crimes.

É válida a reflexão, afinal, conforme já mencionado, esses indivíduos oferecem perigo não só à sociedade, mas também a si mesmo. Sendo assim, é necessário deixar de lado o aparato teórico e utópico de que a medida irá, de fato, curar o paciente, de modo a atingir a possibilidade de reinserção na sociedade, demonstrando, assim, a ineficácia das penas existentes para os indivíduos que são objeto do presente trabalho.

Através do caso de Chico Picadinho é possível perceber o tamanho embaraço existente no que tange tais assassinos, que ora são punidos por meio de penas restritivas de liberdade, ora por meio das medidas de segurança e até mesmo prisões decididas na esfera civil e não criminal, por não possuir aparato suficiente, mantendo o réu preso por mais de quarenta anos e vindo a ser responsabilizado pela justiça cível.

Sendo assim, podemos concluir que é necessário um estudo mais aprofundado sobre o assunto por parte dos legisladores brasileiros, uma vez que a problemática se encontra justamente na dificuldade de recuperação dos indivíduos serial killers, tornando a finalidade da pena de reinserção na sociedade algo muito distante do que a realidade permite. Conhecer e traçar um perfil criminal é fundamental para a imposição de penas, devendo ser bem analisadas em conjunto com outras matérias, como a psiquiatria forense, de forma que seja possível elaborar uma legislação específica que consiga abranger tais pessoas de acordo com seu próprio caso.

\section{REFERÊNCIAS BIBLIOGRÁFICAS:}

BEZERRA. Amanda de Melo. A história completa do maníaco do parque. Youtube. Disponível em: $<$ https://www.youtube.com/watch?v=u2tGsZGtr8k>Acesso em: 20 de abril de 2020

BONFIM, Edilson Mougenout. O Julgamento de um Serial Killer (o caso maníaco do parque). 1. ed. São Paulo. Malheiros Editores. 2004.

BRASIL. Decreto-Lei 7.209, de 11 de julho de 1984. Código Penal. Diário Oficial da União, Rio de Janeiro, 11 de Jul. 1984.

BRASIL. Lei 13.964, de 24 de dezembro de 2019. Aperfeiçoa a legislação penal e processual penal, Brasilia, 24 de dez. de 2019.

BRASIL. Senado Federal. Projeto de Lei do Senado $\mathbf{n}^{\mathbf{0}} \mathbf{1 4 0}$, de 2010 . Acrescenta os $\S \S 6^{\circ}, 7^{\circ}, 8^{\circ}$ e $9^{\circ}$, ao artigo 121 do Código Penal brasileiro (Decreto-Lei $n^{\circ} 2.848$, de 07 de dezembro de 1940) com o objetivo de estabelecer o conceito penal de assassino em série. Disponível em: 
https://www25.senado.leg.br/web/atividade/materias/-/materia/96886 Acesso em: 26 nov. 2019.

BRASIL. Superior Tribunal de Justiça. HC 84219. Min. Marco Aurélio. Primeira Turma. 2005

CARVALHO, Leony Santa Rosa. O "Serial Killer” e o Direito Brasileiro. 1. ed. São Paulo: Leony Santarossa. 2018.

CASOY, Ilana. Arquivos Serial Killer: Louco ou cruel? e Made in Brazil. Rio de Janeiro: DarkSide Books, 2017.

CEOLIN, Emanuela Gonçalves. CARVALHO, Flávio Rodrigo Masson. O psicopata homicida e as sanções penais a eles empregadas no atual sistema penal brasileiro. 2016. Disponível em: https://ambitojuridico.com.br/cadernos/direito-penal/o-psicopata-homicida-e-as-sancoes-penais-a-eleempregadas-no-atual-sistema-penal-brasileiro/\#_ftn69. Acesso em: 25 mar. 2020.

CHAGAS, Camila de Souza. Serial Killer: uma discussão acerca da ineficácia do tratamento penal aplicado aos assassinos em série na perspectiva do direito brasileiro. 2016. Monografia (Bacharelado em Direito). Centro Universitário Tabosa de Almeida ASCES/UNITA, Caruaru, 2016. Disponível em: http://repositorio.asces.edu.br/handle/123456789/563. Acesso em: 25 mar. 2020.

COELHO, Gabriel Alves. A figura do psicopata no direito penal. 2017. Disponível em: https://gabriel1509.jusbrasil.com.br/artigos/445736508/a-figura-do-psicopata-no-direito-penal?ref=serp. Acesso em: 24 nov. 2019.

CUNHA, Rogério Sanches. Manual de Direito Penal: parte geral (arts. $1^{\circ}$ ao 120$)$. Salvador: JusPodivm, 2016.

FENAPEF. Falta de estudos sobre serial killers dificulta julgamentos, afirma promotor. 2010. Disponível em: https://fenapef.org.br/29935/. Acesso em: 17 de novembro de 2020.

GRECO, Rogério. Curso de Direito Penal: parte geral. 18. ed. Rio de Janeiro: Impetus, 2016. v.1.

IPEA. Relatório de pesquisa: Reincidencia Criminal no Brasil. Rio de Janeiro. 2015

MASSON, Cleber. Direito Penal: parte geral. 11. ed. São Paulo: Editora Método, 2017.v.1.

MIRABETE, Júlio Fabbrini. Execução Penal. 10 ed. São Paulo: Atlas, 2002.

NASSARO, Marcelo Robis Francisco. Maus-tratos aos animais e violência contra as pessoas. MPMG Jurídico: Revista do Ministério Público do Estado de Minas Gerais, Belo Horizonte, ed. Defesa da Fauna, p.
$40-47$,
2016.
D i s p o n í v e 1
e $\mathrm{m}$ :

https://aplicacao.mpmg.mp.br/xmlui/bitstream/handle/123456789/1282/MAUSTRATOS\%20AOS\%20ANIMAIS\%20E\%20VIOL\%c3\%8aNCIA\%20CONTRA\%20AS\%20PESSOAS.p df? sequence=1. Acesso em: 26 nov. 2019. 
NEP-FDCL. Motivações patológicas do crime: o exemplo do serial killer. Faculdade de Direito de Conselheiro Lafaiete: Conselheiro Lafaiete, 2012 . Disponível e m: http://nepfdcl.blogspot.com/2012/12/sinopse-motivacoes-patologicas-do-crime.html. Acesso em: 25 de março de 2020.

NUCCI, Guilherme de Souza. Curso de Direito Penal: parte geral: arts. $1^{\text {o }}$ a 120 do Código Penal. - 3. ed. Rio de Janeiro: Forense, 2019.

RAMOS, Késsia de Santana Flório. Serial Killer: prisão ou tratamento. 2017. Monografia (Bacharelado em Direito) Faculdade de Direito de Cachoeiro de Itapemirim, Cachoeiro de Itapemirim, 2017. Disponível em: https://fdci.br/arquivos/200/K__SSIA\%20DE\%20SANTANA\%20FL_RIO\%20RAMOS\%20\%20VIA\%20DEFINITIVA\%20MONOGRAFIA.pdf. Acesso em: 26 nov. 2019.

SCHECHTER, Harold. Serial Killer: Anatomia do Mal. Rio de Janeiro: DarkSide Books, 2013.

SIENA, David Pimentel Barbosa de. Abordagem crítica ao PLS no 140/2010: o "serial killer" como in i m ig o no Direito P e n a 1. 2012 . Dis poníve 1 e m : https://www.direitonet.com.br/artigos/exibir/7041/Abordagem-critica-ao-PLS-no-140-2010-o-serialkiller-como-inimigo-no-Direito-Penal. Acesso em: 02 out. 2019

SOUZA, Danielle Ortiz de Avila. Maníaco do Parque: análise psicopatológica e comportamental. Canal Ciências Criminais, 2019. Disponível em: https://canalcienciascriminais.com.br/maniaco-do-parqueanalise-psicopatologica-e-comportamental/. Acesso em: 23 maio 2020.

VARANDA, Kimberly de Médice. Responsabilidade penal em crimes praticados por doentes mentais. 2017. Monografia (Bacharelado em Direito). Centro Universitário Padre Anchieta, Jundiaí, 2017. Disponível em: https://www.conteudojuridico.com.br/consulta/Monografias-TCC-Teses/51419/responsabilidadepenal-em-crimes-praticados-por-doentes-mentais. Acesso em: 25 mar. 2020.

VILARINHO, Fyallen Melo; LUCENA, Eulineide Lauritzen. A ineficácia das penas brasileiras com relação ao serial killer. Âmbito jurídico: o seu portal jurídico da internet, 2019. Disponivel em: https://ambitojuridico.com.br/cadernos/direito-processual-penal/a-ineficacia-das-penas-brasileiras-comrelacao-ao-serial-killer/> Acesso em 23 de maio de 2020. 